\title{
Fortification strategies to meet micronutrient needs: successes and failures
}

\author{
Ian Darnton-Hill ${ }^{1 *}$ and Ritu Nalubola ${ }^{2}$ \\ 'World Health Organization, 20 Avenue Appia, CH-1211 Geneva 27, Switzerland \\ ${ }^{2} U S$ Food and Drug Administration, Washington, DC, USA
}

\begin{abstract}
Food fortification is likely to have played an important role in the current nutritional health and well-being of populations in industrialized countries. Starting in the early part of the 20th century, fortification was used to target specific health conditions: goitre with iodized salt; rickets with vitamin D-fortified milk; beriberi, pellagra and anaemia with B-vitamins and Fe-enriched cereals; more recently, in the USA, risk of pregnancy affected by neural-tube defects with folic acidfortified cereals. A relative lack of appropriate centrally-processed food vehicles, less-developed commercial markets and relatively low consumer awareness and demand, means it has taken about another 50 years for fortification to be seen as a viable option for the less-developed countries. The present paper reviews selected fortification initiatives in developing countries to identify different factors that contributed to their successful implementation, as well as the challenges that continually threaten the future of these programmes. Ultimately, the long-term sustainability of fortification programmes is ensured when consumers are willing and able to bear the additional cost of fortified foods. There has been an enormous increase in fortification programmes over the last couple of decades in developing countries. Considerable progress has been made in reducing vitamin $\mathrm{A}$ and I deficiencies, although less so with $\mathrm{Fe}$, even as $\mathrm{Zn}$ and folic acid deficiencies are emerging as important public health problems. Food fortification based on sound principles and supported by clear policies and regulations can play an increasingly large role in this progress towards prevention and control of micronutrient malnutrition.
\end{abstract}

\section{Micronutrient malnutrition: Fortification: Vitamin A: Iron-deficiency anaemia: Iodine-deficiency disorders}

Fortification of foods with micronutrients is a technologically, programmatically and economically-effective method of increasing micronutrient intakes in populations (Nestel, 1993; Lotfi et al. 1996; Darnton-Hill, 1998). Food fortification is likely to have played an important role in current nutritional health and well-being of populations in industrialized countries. Starting in the 20th century, fortification was used to target specific health conditions: goitre with iodized salt; rickets with vitamin D-fortified milk; beriberi, pellagra and anaemia with B-vitamins and Fe-enriched cereals; more recently, in the USA, risk of pregnancy affected by neural-tube defects with folic acidfortified cereals.

Fortification is defined by the Codex Alimentarius as the addition of one or more essential nutrients to a food, whether or not it is normally contained in the food, for the purpose of preventing or correcting a demonstrated deficiency of one or more nutrients in the population or specific population groups (Food and Agriculture Organization, 1996). The fortification vehicle can be either a staple food, or a more-processed commercially-available food, and many have been tried. The requirements for a potential food vehicle for fortification are well established (Table 1; Food and Agriculture Organization, 1996).

There is now extensive literature on food-fortification programmes, especially recently in the non-industrialized world (Nestel, 1993; Lotfi et al. 1996; Micronutrient Initiative, 1997; Darnton-Hill, 1998). Fortification of foods is one intervention for the prevention and control of micronutrient malnutrition, along with other food-based approaches and supplementation, the mix of interventions depending on the local situation, experience, commitment and resources, and infrastructure. Fortification has the advantage of requiring relatively less change in consumer behaviours and food habits than the other interventions, although this approach does not mean that nutrition 
Table 1. Requirements for a food vehicle for fortification (Food and Agriculture Organization, 1996)

Commonly consumed by the target population

Constant consumption pattern with a low risk of excess consumption Good stability during storage

Relatively low cost

Centrally processed with minimal stratification of the fortificant

No interactions between the fortificant and the carrier food

Contained in most meals, with the availability unrelated to socioeconomic status

Linked to energy intake

education and social marketing can be ignored. Without convincing consumers and policy makers of the need and benefits of fortification, its sustainability will always be at risk.

A relative lack of appropriate centrally-processed food vehicles, less-developed commercial markets and relatively low consumer awareness and demand has meant that another 50 years passed before fortification was seen as a viable option for the less-developed and industrializing countries. The minimisation of many of these earlier constraints and the increasingly global market, has led to a great deal of current interest in the use of fortification as one approach to the prevention and control of micronutrient malnutrition. The present paper will (1) outline the various strategies available for fortification of foods in the prevention and control of micronutrient malnutrition, (2) review currently successful programmes in developing countries and the elements of success, some past illustrative failed programmes and identified constraints, monitoring and evaluation and (3) finally, identify some innovations in the field, followed by conclusions.

\section{Fortification as a means of addressing micronutrient malnutrition}

Over 2000 million of the world's population, or more than one in three individuals throughout the world, are at risk of Fe, vitamin A or I deficiency (World Health Organization, 1995; Micronutrient Initiative, 1997). $\mathrm{Zn}$, folic acid and other micronutrients are also increasingly being recognized as public health problems in many disadvantaged populations. The public health importance of micronutrient malnutrition in the developing world was recognized and acknowledged globally in December 1992, at the FAO/WHO International Conference on Nutrition, where representatives of 159 countries agreed to eliminate the I-deficiency disorders and vitamin $A$ as public health problems by the end of the century and to substantially reduce $\mathrm{Fe}$-deficiency anaemia by one-third of the 1990 levels. In 1990 the World Summit for Children, sponsored by UNICEF, had established broader goals for the health and well-being of children (UNICEF, 1990), and the nutrition goals, including those for micronutrients, agreed to at this forum were echoed at the International Conference on Nutrition. It is likely that these goals will be re-affirmed and extended at a UN Special Session on Children to be held in May 2002. The proposed goals are to 'achieve sustainable elimination of iodine deficiency disorders by 2005 and vitamin A deficiency disorders by 2010 , reduce by one third the prevalence of anaemia, including iron deficiency, by 2010 , and accelerate progress towards reduction of other micronutrient deficiencies, through food fortification and supplementation.' It is notable that this time, one decade after the 1992 International Conference on Nutrition declaration, fortification is specifically mentioned as an intervention strategy.

The World Bank (1993) has identified micronutrient interventions in general, and food fortification in particular, as amongst the most cost-effective of all health interventions and as a major factor in the control of the micronutrient deficiencies in the industrialized world. In the past fortification efforts have been less effective, both in terms of start-up and sustainability, in developing countries compared with the more industrialized world. However, in the last few years the experience in many countries of Latin America, especially with vitamin A in sugar (Mora et al. 2000) and with Fe and B-vitamins in cereals indicates the potential for considerable expansion of fortification as an approach to address micronutrient malnutrition in the developing world (Murphy, 1996). Indeed, fortification of appropriate food vehicles is being used as a public health intervention in many developing countries, as will be discussed.

\section{Successes in developing countries}

Food-fortification programmes that have been successfully implemented in developing countries have been reviewed previously (Nestel, 1993; Lotfi et al. 1996; Darnton-Hill, 1998) and, therefore, are only summarized here. Table 2 presents foods that are fortified under mandatory fortification regulations in selected developing countries. The most common food-fortification practice has been salt iodization, which has been in existence for over 70 years (Bürgi, 1998). Its success has been largely through its relative simplicity and low cost, but also the more recent international endorsement and advocacy and its coalition of partners. In 1994 UNICEF and WHO recommended universal salt iodization as the prime approach to correcting I deficiency in the many countries where it is a public health problem. In 1992 at the 7th World Salt Symposium in Kyoto, Japan introduced the global elimination goal in a special session presented by International Council for the Control of the Iodine Deficiency Disorders Board members. Following the introduction of this goal, in 1993 Kiwanis International, the worldwide service organization, became an important contributor. Finally, at the 8th Session of the World Salt Symposium at The Hague in 2000, the salt industry publicly accepted their specific role and responsibility for delivering the fortified product and the service necessary in achieving and sustaining this goal (International Council for the Control of the Iodine Deficiency Disorders, 2000a). Today, almost 126 countries in the developing world have salt-iodization programmes in place (Mason et al. 2001).

During the 1970s sugar fortification with vitamin A was first implemented in Guatemala, followed by other Central American countries, including Costa Rica, Honduras and $\mathrm{El}$ Salvador. Although the programmes have been suspended at 
Table 2. Mandatory food fortification programmes in developing countries (from Nutriview, 2000)

\begin{tabular}{|c|c|c|}
\hline Country & Food vehicle(s) & Nutrient \\
\hline Bolivia & Wheat flour & Thiamine, riboflavin, niacin, folic acid, $\mathrm{Fe}$ \\
\hline Brazil & Dried skimmed milk for complementary food programmes & Vitamins $A$ and $D$ \\
\hline \multirow[t]{3}{*}{ Chile } & Wheat flour & Thiamine, riboflavin, niacin, folic acid, Fe \\
\hline & Pasta & Thiamine, riboflavin, niacin, $\mathrm{Fe}$ \\
\hline & Margarine & Vitamins $A$ and $D$ \\
\hline \multirow[t]{2}{*}{ Colombia } & Wheat flour & Thiamine, riboflavin, niacin, folic acid, Fe \\
\hline & Margarine & Vitamins $A$ and $D$ \\
\hline \multirow[t]{2}{*}{ Costa Pica } & Wheat flour & Thiamine, riboflavin, niacin, folic acid, Fe \\
\hline & Sugar & Vitamin A \\
\hline Dominican Republic & Wheat flour & Thiamine, riboflavin, niacin, folic acid, Fe \\
\hline \multirow[t]{2}{*}{ Ecuador } & Wheat flour & Thiamine, riboflavin, niacin, folic acid, $\mathrm{Fe}$ \\
\hline & Margarine & Vitamins $A$ and $D$ \\
\hline \multirow[t]{2}{*}{ El Salvador } & Wheat flour & Thiamine, riboflavin, niacin, folic acid, Fe \\
\hline & Margarine, sugar & Vitamin A \\
\hline \multirow[t]{4}{*}{ Guatemala } & Wheat flour & Thiamine, riboflavin, niacin, folic acid, $\mathrm{Fe}, \mathrm{Ca}$ \\
\hline & Pasta & Thiamine, riboflavin, niacin, $\mathrm{Fe}$ \\
\hline & Skimmed milk & Vitamins $A$ and $D$ \\
\hline & Margarine, sugar & Vitamin A \\
\hline \multirow[t]{3}{*}{ Honduras } & Wheat flour & Thiamine, riboflavin, niacin, folic acid, $\mathrm{Fe}$ \\
\hline & Milk, margarine & Vitamins $A$ and $D$ \\
\hline & Sugar & Vitamin A \\
\hline Mexico & $\begin{array}{l}\text { Sterilized low-fat milk, pasteurized low-fat milk, evaporated } \\
\text { whole and low-fat milk, margarine/spreads }\end{array}$ & Vitamins $A$ and $D$ \\
\hline \multirow[t]{2}{*}{ Nicaragua } & Wheat flour & Thiamine, riboflavin, niacin, folic acid, Fe \\
\hline & Sugar & Vitamin A \\
\hline \multirow[t]{2}{*}{ Panama } & Wheat flour & Thiamine, riboflavin, niacin, folic acid, Fe \\
\hline & Sugar & Vitamin A \\
\hline Paraguay & Wheat flour & Thiamine, riboflavin, niacin, folic acid, $\mathrm{Fe}$ \\
\hline \multirow{2}{*}{ Peru } & Wheat flour & $\mathrm{Fe}$ \\
\hline & Margarine & Vitamins $A$ and $D$ \\
\hline \multirow{3}{*}{ Venezuela } & Wheat flour & Thiamine, riboflavin, niacin, $\mathrm{Fe}$ \\
\hline & Precooked maize flour & Thiamine, riboflavin, niacin, vitamin $\mathrm{A}, \mathrm{Fe}$ \\
\hline & Dried milk powder & Vitamins $A$ and $D$ \\
\hline Nigeria & Enriched flour & Thiamine, riboflavin, niacin, $\mathrm{Fe}, \mathrm{Ca}$ \\
\hline \multirow[t]{2}{*}{ South Africa } & Enriched maize meal & Riboflavin, niacin \\
\hline & Margarine & Vitamins $A$ and $D$ \\
\hline Zambia & Sugar & Vitamin A \\
\hline India & Vanaspati, margarine & Vitamin A \\
\hline \multirow[t]{2}{*}{ Indonesia } & Wheat flour & Thiamine, riboflavin, $\mathrm{Fe}, \mathrm{Zn}$ \\
\hline & Margarine & Vitamins $A$ and $D$ \\
\hline \multirow[t]{2}{*}{ Malaysia } & Evaporated milk, condensed milk, filled milk & Vitamin A \\
\hline & Table margarine & Vitamins $A$ and $D$ \\
\hline & Oil products (ghee, butter oil) & Vitamin A \\
\hline \multirow{2}{*}{ Philippines } & Filled milk & Vitamins $A$ and $D$ \\
\hline & Margarine & Vitamins $A$ and $D$, thiamine \\
\hline Thailand & Sweetened condensed milk & Vitamin A \\
\hline Turkey & Table margarine & Vitamins $A$ and $D$ \\
\hline
\end{tabular}

various times since their inception due to political and other constraints, all three countries currently operate successful sugar-fortification programmes because of active collaboration between the public and private sectors. The programmes are estimated to reach about $95 \%$ of households in El Salvador and Guatemala, and more than $80 \%$ of households in Honduras (Mora et al. 2000). The success of these programmes provided the impetus for sugar fortification to be explored as an effective intervention strategy in other developing countries. Fortification of sugar with vitamin A was initiated in 1998 in Zambia and is ongoing despite economic constraints, including the falling international price of sugar and the continuous infiltration of cheaper unfortified sugar from bordering countries. Currently, other African and Asian countries are also exploring the feasibility of sugar fortification with vitamin A (Micronutrient Initiative/UNICEF/International Sugar Organization/USAID/Swaziland Sugar Association, 1999).

Other food vehicles, besides sugar, fortified with vitamin A include fats and oils, tea, cereals, flour, monosodium glutamate and instant noodles, as well as milk or milk powder, whole wheat, rice, salt, soyabean oil and infant formulas (Nestel, 1993; Lotfi et al. 1996). At least one common brand of margarine is currently fortified with vitamin $\mathrm{A}$ in the Philippines, along with fourteen other foods commercially available, and efficacy has been 
demonstrated for margarine (Solon et al. 1996), although it is unclear if the at-risk rural poor are being reached. Similarly, the feasibility and efficacy of vitamin A added to wheat flour fortified with $\mathrm{Fe}$ and $\mathrm{B}$-vitamins has been tested in a small-scale trial in the Philippines (Solon et al. 2000). Although the implementation aspects and the effectiveness of such a fortification programme still need to be clarified, over half the flour millers have agreed to fortify, and legislation has recently been enacted. Malaysia has done much work with retaining the $\beta$-carotene content of refined red palm oil (Ong, 1994), and the use of red palm oil as a vitamin A fortificant added to other edible oils is being explored in Asia (Solomons, 1998) and in West Africa. Additionally, noodles (or the accompanying sauce or spices sachet) are increasingly being used as vehicles for vitamin A fortification in South East Asia (Nutriview, 2000). Twentynine developing countries are now actively fortifying, or are in advanced development stage, a range of foods with vitamin A (Mason et al. 2001).

Fortification of cereal products with Fe and B-vitamins has been in practice for a number of years throughout the developing world (Johnson, 2000). Fortification with multiple micronutrients is increasingly being used as micronutrient deficiencies tend to manifest concurrently in at-risk populations. Several Latin American countries have extensive experience fortifying maize flour and maize meal with $\mathrm{Fe}$, thiamin, riboflavin and niacin, and more recently with folic acid and vitamin A. Wheat-flour fortification is now policy in most countries in Central and South America (Darnton-Hill et al. 1999). Cereal flour or meal fortification with B-vitamins, Fe, and sometimes vitamin A, is going ahead in several Middle East countries (A Verster, personal communication), and is being explored in many more throughout Asia and Africa (Nutriview, 2001). Fe-fortification programmes have faced several daunting challenges, technological as well as programmatic. Achieving a balance between the bioavailability of the Fe fortificant, its cost and its stability in foods has been a major challenge in delivering $\mathrm{Fe}$ through foods to at-risk populations. Another challenge has been the lack of a clear demonstration of benefit of national Fe-fortification programmes to at-risk population groups, including children. The multi-factorial causative factors of anaemia, including non-dietary factors such as helminth infestations, further adds to the challenge of demonstrating a benefit of $\mathrm{Fe}$ fortification of foods. Nevertheless, thirty countries throughout the developing world now have a range of commodities (mainly wheat flour but also maize flour, milk, rice and weaning foods) that have fortification programmes with $\mathrm{Fe}$ actively in place, although to a greater or lesser extent (Mason et al. 2001).

The factors contributing to the success of established food-fortification programmes both in the industrialized and developing countries have been previously addressed (Nestel, 1993; Darnton-Hill, 1998; Asian Development Bank/Micronutrient Initiative/International Life Sciences Institute, 2000; Bishai \& Nalubola, 2002). However, relatively little is known about the impact of fortification programmes, primarily due to the limited number of good assessments that have been conducted or documented. Nevertheless, there are some data available which highlight the potential effectiveness of a properly-implemented fortification programme. A recent evaluation of the possible health impact of niacin fortification of flour and bread in the USA showed that food fortification played an important role in the decline of pellagra-attributed mortality in the 1930s and 1940s, and finally, in the elimination of pellagra in the USA (Park et al. 2000). Anaemia and vitamin A deficiency ceased to be public health problems in Newfoundland, Canada only after the fortification of margarine and flour in 1945 (Micronutrient Initiative, 1997). Folic acid fortification of cereal products was authorized in the USA in 1996 as a public health measure to decrease the risk of pregnancy affected by neural-tube defects. Since the programme began neural-tube birth defects have decreased by $19 \%$, and fortification, educational outreach and increased consumer awareness have been noted to contribute to this decrease (Caudill et al. 2001; Center for Disease Control, 2001; Honein et al. 2001).

National programmes of sugar fortification with vitamin $A$ in Central American countries have been evaluated for their effects on vitamin A deficiency in at-risk population groups. National surveys conducted between 1995 and 1998 in Guatemala, Honduras and El Salvador have shown clear reductions in the prevalence of vitamin A deficiency among preschool-age children (Mora et al. 2000). The primary source of dietary vitamin $\mathrm{A}$ in these countries has been found to be fortified sugar, with a coverage of $>80 \%$ of the households in these countries. When fortification was halted in the 1980s for various political reasons in Guatemala, vitamin A deficiency prevalence was found to have increased (Arroyave et al. 1979; Mora et al. 2000; Dary, 2001).

The effectiveness of $\mathrm{Fe}$-fortification programmes in combating anaemia has been less clear. In 1994 Sweden ceased fortifying its bread because of a lack of perceived benefit in a replete society, although this action is currently being re-evaluated. In Venezuela fortification of wheat and maize flours with $\mathrm{Fe}, \mathrm{B}$-vitamins and vitamin $\mathrm{A}$ was initiated in 1993, and a preliminary survey carried out among a small group ( $n$ 307) of children in 1994 showed that the prevalence of $\mathrm{Fe}$ deficiency and anaemia had decreased significantly $(P<0.05)$ (Layrisse et al. 1996). The mean average increase in $\mathrm{Fe}$ intake of $6 \mathrm{mg} / \mathrm{d}$ that was observed is similar to that found in other interventions in Latin America, South Africa and Thailand (Beard, 1996). A large-scale effectiveness trial of wheat-flour fortification with two different $\mathrm{Fe}$ fortificants, electrolytic $\mathrm{Fe}$ and hydrogen-reduced $\mathrm{Fe}$, has been completed recently in Sri Lanka, and results from this trial are awaited (P Nestel, personal communication).

A single micronutrient addition to an appropriate food vehicle is increasingly the less common approach in foodfortification programmes. As Huffman et al. (1998) have shown, women in developing countries are often consuming diets of poor bioavailability and limited micronutrient content, leading to concurrent deficiencies of $\mathrm{Fe}$, vitamin $\mathrm{A}$, $\mathrm{Zn}$, folic acid and vitamins $\mathrm{B}_{6}$ and $\mathrm{B}_{12}$, and occasionally other vitamins and minerals. Such deficiencies have important consequences for women's own health, pregnancy outcomes and their breast-fed children's health and nutritional status (Huffman et al. 1998). UNICEF has 
recently recommended that a combined vitamin-mineral supplement for pregnant women, similar in composition to those freely available in the more industrialized world is an option that needs to be considered for developing countries (UNICEF/World Health Organization/United Nations University, 1999).

Fortifying foods with multiple micronutrients is another avenue to deliver micronutrients, complementing supplements. This approach is important, as supplementation may not reach non-pregnant women, female adolescents and young children, who are not usually being directly targeted by supplementation programmes, but who might be reached by appropriately fortified foods. One example is the VitaLeite programme in the State of Sao Paulo in Brazil, where the distribution of free milk fortified with vitamins A and $\mathrm{D}$ and $\mathrm{Fe}$ is targeted to over 700000 poor families. A small survey ( $n 269$, children aged 6 months-2 years) in Angatuba found anaemia prevalence dropped from $62.3 \%$ to $26.4 \%$ in 1 year (Ferrer, 2001). In Asia, at least, investment per head in fortifying staples and complementary foods for older infants is one-tenth that of supplementation programmes (Mason et al. 1999). Fortification of complementary foods has been shown not only to improve the status of the young child, but where the community is involved, to empower the women in these communities. Another important delivery mechanism using fortification is the internationally-recognized imperative of fortifying all food used in humanitarian aid, although this provision is tragically occasionally still not made.

\section{Elements of successful fortification in industrializing countries}

From the experiences of successful fortification programmes, facilitating factors have been briefly summarized (Darnton-Hill, 1998) as the following:

political will and support, which must be maintained from the development stage;

understanding of the problem by having adequate data on the magnitude of the nutritional problem being addressed;

adequate data on food-consumption patterns; support of industry, with early involvement of local industry and the private sector;

adequate technical expertise, proper testing under a range of real field conditions, and adequate training in fortification technology, quality assurance and control; a multi-sectoral approach in establishing a programme, including key governmental organizations, the scientific community, consumers, marketing specialists and other relevant interested parties early in the process;

adequate application of legislation and regulations, including resources for effective enforcement; facilitative rather than punitive regulations, i.e. guidelines should not be so restrictive as to impede the provision of high-quality fortified foods nor hinder communication on fortification between relevant parties;

human resource training at the industry and marketing levels and of public health and food-safety personnel; appropriate fortification levels evaluated and adjusted according to the bioavailability of the nutrient in the diets of the target population;

good bioavailability of the compound and no constraints on procurement of the micronutrients, e.g. financial support for initial batch of fortificant;

intensive and appropriate investment in the information, education and communication about the problem and the fortification approach to raise consumer awareness and ensure consumer acceptability, and also to ensure that there are no cultural or other objections against fortified foods;

minimal cost increase to the consumer, to the extent feasible;

relevant nutritional information available through adequate labelling to help ensure consumer involvement, commitment and understanding of the advantages of fortifying foods.

\section{Programmes and problems}

An innovative approach to vitamin A deficiency in Bangladesh was tried in the late 1980 s, whereby a shellac containing vitamin A was to be sprayed on wheat coming in as aid wheat from the USA. As wheat was much the lesspreferred staple, this cereal had the added advantage of being indirectly targetted to the very poor, those in the vulnerable-group feeding programme of the UN World Food Programme. Although it was new technology, it was very extensively developed and tested and was technically feasible (Darnton-Hill, 1989). After a great deal of effort it finally became untenable and politically unacceptable; partly, it appeared that there was concern about a foreign power being involved in the food system, rumours about the fortificant and it was also probably insensitively handled (Darnton-Hill, 1989). Atta (ground wheat flour) may be fortified now through a partnership of UN World Food Programme, USAID and the Government of Bangladesh, and the millers. A similar process occurred with vitamin A in monosodium glutamate in Indonesia; again a combination of technology and politics led to this programme being stopped by the government after extensive laboratory work, efficacy trials and a successful effectiveness trial (Muhilal et al. 1988). Although the microencapsulated vitamin A remained white in rigorous laboratory testing, when hanging in the sun in small cellophane packets outside the small rural sarisari shops there was enough discolouration to concern the producer who sold monosodium glutamate as the whitest of white products, and who had anyway been excluded from the early planning ( $\mathrm{R}$ Tjiong, unpublished results). There was also some concern from professional medical associations and the government about possible toxicity of monosodium glutamate, although it is not classified as such by Codex Alimentarius.

The fortification of sugar with vitamin $A$ in the Philippines did not go ahead when the world market price plummeted just a few months after the launch in February 1997; the sugar company was sent into financial crisis and then had to withdraw (FS Solon, personal communication), but sugar fortification is now being tried again. In Zambia, while certainly not a failure, results are still awaited due to 
problems with private sector commitment, price of fortificant and the considerable duty to be paid on the fortificant, which the government has said it will lift, but has not yet done so.

With the iodization of salt in the Philippines, a monopoly was given to a single producer as an incentive, but it was not then produced as anticipated. Special provisions given to one firm to encourage start-up action can distort incentives for other companies, as happened in this case, when the concession of an extended monopoly effectively inhibited competitors from also fortifying salt. The national parliament of India recently repealed legislation that mandated universal iodization of salt, thus turning a success story into a potential failure. This action hinged on arguments of personal rights of access to non-iodized salt, and underlines the importance of consumer education and political will. It seems the Indian states may enact their own legislation. However, as was the case with the cantons of Switzerland (Bürgi, 1998), some states will be considerably more pro-active about enacting legislation than others. With all fortification programmes there is concern about the leakage of non-fortified (and hence usually cheaper) foods across borders, e.g. leakage of non-iodized salt across borders in Africa. Some apparent success stories, such as the iodization of salt in Eritrea and its export to neighbouring countries, collapsed under the pressure of the conflict with Ethiopia. Another such reverse occurred in Sierra Leone, where iodized salt coverage declined from $75 \%$ to $8 \%$ in 1999 due to the civil war (International Council for the Control of the Iodine Deficiency Disorders, 2000b).

Similarly, in the USSR, where severe I-deficiency disorders had been eliminated by effective control measures as early as the $1940 \mathrm{~s}$ and $1960 \mathrm{~s}$, government programmes were discontinued in 1970. After the dissolution of the USSR in 1991, I-deficiency disorders again became a common problem in nearly all the newly-independent states (Gerasimov \& Delange, 1998). Dary (2001) sees such reversals as a continuing tension between the needs of 'free trade' and 'public health', and that legislative tools may be insufficient without reliable enforcement mechanisms and consumer awareness.

\section{Constraining factors in non-sustained programmes}

A recent review of food-fortification practices, which started as public health intervention programmes early in the 20th century in the USA, concluded that the primary factor contributing to the long-term sustainability of food fortification is consumer awareness of the nutrient deficiency and consumer demand for and perceived benefits of the fortified food (Bishai \& Nalubola, 2002). It has become apparent that constraining factors in non-sustained programmes in developing countries are the lack of consumer demand due to a non-recognition of any likely benefits to come from consuming fortified foods, as well as the lack of public sector policy makers' recognition of the nutrient deficiencies as a public health problem. That fortification requires minimal consumer involvement and little-to-no change in dietary habits is often stated as an advantage of food fortification over other interventions. In the past this approach has been construed to mean that there is therefore no need to educate the public of the need and role of food fortification, and the result was less emphasis on consumer education in national fortification programmes. The importance of advocacy at the political level, as well as raising consumer awareness regarding the magnitude and effects of the nutrient deficiency, and the role of fortification as a complementary approach to other interventions, need to be recognized as prerequisites for success (Micronutrient Initiative, 1997). A recent example of this approach was the previously mentioned revoking of universal iodization of salt in India, but examples could be quoted from European countries with long histories of iodization, such as Switzerland, where the programme continues to need constant monitoring and adjustment, in particular in response to importation of food prepared with non-iodized salt (Bürgi, 1998).

The socio-economic constraints faced by consumers when fortified foods are being promoted, and the likely benefits of food fortification, are now being increasingly recognized as critical factors in gaining public and private sector commitment to, and eventually the success of, a fortification programme, and these factors need to be addressed early. Ignoring these factors has been shown to contribute to the failure of programmes. Nevertheless, even with the best social marketing, price can remain a constraint. In very poor households there is very little price elasticity, and even a minimal increase can discourage the buying of fortified foods. In a study in South Kalimantan and South Sulawesi in Indonesia it was found that while instant noodles were consumed in nearly all households in both areas, consumption of fortified noodles was related to socioeconomic status and was lowest among farmers and share croppers, who might well be some of those most at risk (Melse-Boonstra et al. 2000).

These and other constraints can be summarized as the following:

technical constraints: installation and maintenance of fortification machinery; stability of fortificants under the suboptimal distribution and storage conditions traditionally found in developing countries; the development of new cost-effective fortificants;

socio-economic constraints: the targeted groups are often those with least purchasing power; price of initial batch of fortificant and capital costs; the demand on foreign exchange;

infrastructural constraints: poor distribution systems due to poor infrastructure; lack of access to commerciallyprocessed food limited by geography, poverty or cultural preferences; limited experience of intersectoral coordination; frequent changes of government;

political constraints: political support may be lacking due to perceived priority of other health and nutrition interventions; lack of awareness of magnitude of problem and benefits of addressing it; lack of facilitating legislation and of equal opportunities for all potential fortifying companies;

other implementation constraints: often there is a lack of a clearly appropriate food vehicle that addresses all the desirable qualities of Table 1; weak quality assurance systems at the private sector level; ineffective 
enforcement of any existing fortification regulations at the public sector level; a lack of proper monitoring and evaluation of the programme and, therefore, limited intermediate corrective follow-up measures. Perhaps the greatest potential constraint is who bears the added cost, e.g. to the millers, the added cost is the sum of premix, equipment amortization, labour and quality control. To these factors must be added advocacy, social marketing, increased public awareness, monitoring and effectiveness of quality assurance, and someone must pay for all this additional cost, however small the actual amount (Micronutrient Initiative, 1997).

\section{Monitoring and evaluation as a critical factor in the sustainability of fortification}

As discussed earlier, the success of fortification programmes depends on several essential factors. One of the critical ones that is needed for long-term sustainability is discussed in detail here, not because it is more important than the others discussed earlier, but primarily because it is largely ignored in the implementation of fortification programmes. Monitoring and evaluation are critical aspects of a fortification programme, and a key constraint for countries with limited funds. The current trend is towards a public-private sector collaboration, with facilitative legislation and quality assurance by the fortifying company. It is recommended that any new legislation sets forth in the regulations the requirements and standards for food fortification, rather than amending the food laws in a piecemeal fashion to address fortification of a particular food vehicle with a particular nutrient (Nathan, 2000). This approach puts the onus on the commercial company itself to assure the quality of the fortified food. It is not clear, however, whether this system has necessarily been successful, even though it is frequently cited as a prerequisite to sustained food fortification.

Monitoring includes measures taken by the private and public sectors to assure that the food is fortified at adequate levels and is properly labelled when it reaches the consumer. A good monitoring system needs specific mechanisms for prompt corrective actions to be taken by relevant parties when problems are identified. Evaluation includes: identifying patterns of consumer behaviour in terms of the purchase and consumption of the fortified food; determining intake of the nutrient of interest and the contribution of the fortified food to this intake (in the case of multiple micronutrient fortification, one nutrient may be chosen as an indicator); impact on the public health problem being addressed. As discussed earlier, few programmes have been properly evaluated and impact on public health determined, although some successful programmes have been shown to have had the intended health benefits. Despite economic constraints, evaluation should be given more emphasis in the design and implementation of fortification. It has been shown that demonstrating the public health benefits of fortification programmes is critical in long-term sustainability and in gaining the commitment of public and private sectors as well as consumer demand for the fortified food (Mora et al. 2000; Bishai \& Nalubola, 2002). The Institute of Medicine of the US National Academy of Sciences also identified demonstrated feasibility, along with efficacy, appropriateness and political commitment, as essential for sustainability (Institute of Medicine, 1998). In this report the authors point out that sustainability has two components: process, the continuity of a successful intervention; outcomes, continuation of a substantial positive impact on the intended beneficiaries.

Surveillance systems set up to observe trends in the prevalence of the public health problem over time help evaluate the impact of the fortification as well as other intervention programmes. For example, in Australia and the USA it seemed that I levels may have needed to be reduced, largely because individuals are getting I from other sources, e.g. in bread, and when iodophors are used to clean cow's udders. Urinary I was measured in the National Health and Nutrition Examination Survey (NHANES) I (1970-4), and found to be higher than desirable, which prompted bans on some iodophors and adoption of alternatives for $I$ in dairy operations. However, the median concentration decreased more than $50 \%$ between 1971-4 and 1988-94 (NHANES III). These findings, although not indicative of I deficiency in the overall US population, were considered to define a trend that needed monitoring (Hollowell et al. 1998). On the other hand, in European countries, at times, I levels have decreased even when fortification has been in place for many years; for example, Germany, after the adoption of the 'principles of voluntary action' following reunification (Meng \& Schindler, 1998), and in Switzerland, where to correct for falling levels of urinary $I$ it was decided to raise the salt I to $20-30 \mathrm{mg} / \mathrm{kg}$ in 1998 (Bürgi, 1998). Europe has had fortification for over 70 years now, and still has not achieved true sustainability, as evidenced in the rising rates of I-deficiency disorders in the Eastern Block countries (Gerasimov \& Delange, 1998), and as in the examples of Germany and Switzerland.

Monitoring and evaluation is also helpful to address concerns of safety of food fortification. For example, concern has been expressed in the case of vitamin A fortification, especially when several foods are fortified. An intake of $3 \mathrm{mg} / \mathrm{d}$ has been set as the level safe for adults, including pregnant women. Excessive amounts of vitamin A are known to have teratogenic effects in pregnant women, especially during the first few weeks of pregnancy. In developing countries, where levels of fortification are poorly monitored, the introduction of several commercial foods each fortified with up to $100 \%$ of the recommended daily intake for vitamin A might lead to potentially unacceptable levels of vitamin A intake in pregnant women. However, it should be noted that at the levels of fortification currently practised around the world, enormously high and practically impossible amounts of an individual food or a combination of fortified foods would have to be consumed on a daily or regular basis to reach this toxicity threshold for human subjects. Thus, vitamin A toxicity from fortified foods is highly unlikely. Indeed, even in developed countries where many foods may be fortified with vitamin A, there have been no reports of vitamin A toxicity attributed to the intake of fortified foods (Nalubola, 2000). A case study of vitamin fortification in the USA shows that, although many foods are fortified with vitamin $\mathrm{A}$ in the USA and, according to NHANES III, about $40 \%$ of the US 
population regularly consumes dietary supplements, there have been no reports to date of vitamin A toxicity through fortified foods in the USA (Nalubola, 2000).

Nevertheless, theoretical concerns continue to be of relevance when a programme is being started. Sometimes these are real concerns, which is where monitoring is essential. In Zimbabwe, and later in the People's Republic of Congo, there were several reports of salt fortification with I in communities with chronic I deficiency leading to potentially fatal cases of Jodbasedow or I-induced hyperthyroidism disease (Delange, 1998; International Council for the Control of the Iodine Deficiency Diseases, 2000b). These cases were found to be due to poor or absent monitoring, and sudden introduction of overly-fortified salt coming in from surrounding countries (Todd et al. 1995). A more theoretical possibility is Fe overload, especially in Caucasian men suffering from a tendency to haemochromatosis. With the exception of massive amounts of $\mathrm{Fe}$ in locally-brewed beer in south and east Africa, this potential overload does not appear to be a real concern in developing countries where Fe deficiency is widespread (Harvey et al. 2000).

Given the presumed success of fortification in the industrialized countries, coupled with the greater demonstrated need in developing countries, fortification should be actively pursued in the developing world. It has been shown in Europe that adults and children who include fortified foods in their diets have higher micronutrient intake and status compared with those who do not (McNulty, 1999; Serra-Majem, 2001). There is also evidence that fortification may be particularly important in contributing to the micronutrient status in those with low nutrient intakes generally (McNulty, 1999). It remains for this possibility to be confirmed in the developing world. The most pressing factor to be actively addressed is the development of adequate monitoring mechanisms that must be in place.

\section{Innovations}

While much of the fortification technology and implementation is transferable to developing countries, based on the relatively long experience in the industrialized countries, it may need new approaches or innovative thinking in order for the programmes to benefit the target population. This requirement for innovation is for all the reasons discussed earlier, but probably the overwhelming one is that the target populations are most often poor, relatively isolated and somewhat out of the global or even national market. Other facilitating groups may need to be involved, e.g. the nongovernmental organizations that have been instrumental in testing the feasibility of hammer-mill stage fortification of maize in Africa. Maize meal fortification and hammer-mill technology is currently being tested for effectiveness in Zimbabwe. Families when they bring their maize to the hammer mill are offered a sachet of premix (vitamin A, B-vitamins, Fe and $\mathrm{Zn}$ ) costing approximately \$US 0.80 to add to $20 \mathrm{~kg}$ maize meal. Evaluated after 1 year, half of all maize in the operational research area was being fortified (although the local mixing process was seen as taking too long and a constraint; Lindsey \& Kwaramba, 2001).
Similar pilot schemes are also being undertaken in Malawi, Mozambique, Tanzania and Zambia. Quality assurance clearly becomes a challenging issue under these circumstances. Mobile self-contained mills for fortifying maize in refugee camps are also being tried. The UN World Food Programme is involved in Bangladesh and Afghanistan; in Afghanistan the World Food Programme is facilitating local fortification of its flour with vitamin A, thiamine, riboflavin, niacin, folic acid and Fe.

Exactly what is meant by fortification and what constitutes a fortified food has expanded. These definitions now include: a single micronutrient added to food, multiple micronutrients added to foods (e.g. triple fortification of salt); supplements (e.g. 'sprinkles') added to weaning foods and porridges; foods bioengineered to contain micronutrients that are not present in the traditional varieties; vastly improved fortification techniques, allowing for multiple, stable and acceptable fortification. 'Sprinkles' are microencapsulated micronutrients, including ferrous fumarate, which are available in a single-dose sachet, and can be sprinkled onto complementary and weaning foods, and other foods. In a randomized controlled trial in Ghana they were found to be as efficacious as Fe-containing drops in the treatment of anaemia (Zlotkin, 2001).

While multiple fortification has always been used in flour and breakfast cereals, many micronutrients are now being added to other commercially-processed foods, including confectionery foods in Indonesia (Sari et al. 2001), fortified drinks in Nicaragua, Peru, the Philippines and Tanzania (Micronutrient Initiative, 1997; Ash et al. 1999; Solon et al. 2001), and shortbread type biscuits in South Africa (van Stuijvenberg et al. 1997). An example of the technological innovations being explored is the double or triple fortification of salt with I, Fe and vitamin A, where the nutrients are microencapsulated to minimize cross-reactivity and improve stability. Preliminary studies to determine the feasibility of this technology are now underway in India and Indonesia, and may be expanded to Kenya and Nigeria (Micronutrient Initiative, 1997). The efficacy of fortifying fish sauce with $10 \mathrm{mg}$ Fe as NaFeEDTA in $10 \mathrm{ml}$ fish sauce has been demonstrated in Vietnam (Thuy et al. 2001) and trials of Fe fortification of soya sauce are well underway in China (Fidler et al. 2001).

\section{Conclusions}

There is a clearly identified need for interventions to combat micronutrient deficiencies worldwide. In the more affluent industrialized countries these have been, and continue to be, addressed by food fortification, as well as by overall economic growth and general improvements in health, sanitation and nutrition that have contributed to the prevention and control of these deficiencies. These same aspects must be addressed in any prevention and control programmes in non-industrialized countries. Fortification, supplementation, other food-based approaches and complementary public health measures are all necessary. This process can only be carried out by partnerships with government, industry and the consumer. There is a need to assess more widely the impact of interventions, not least for advocacy. Ultimately, the success, impact and sustainability 
of food fortification, like other interventions, rest with educating the consumer, developing consumer demand and demonstrating impact.

Successful fortification programmes have been identified as needing at least the following: strong political commitment and the ability to enforce regulations in a facilitative manner; early private sector involvement and willingness to comply with regulations; public sector backing including endorsement by professional medical organizations and financial support by donors; strong and active consumer education to raise consumer awareness and promote demand. Equally important is the necessity for a sound scientific basis in the design of any fortification intervention, including: documentation of the severity and effects of the deficiency in the relevant population groups; data on food consumption patterns, along with technological and market feasibility assessments; measures to monitor and evaluate the implementation of the intervention, followed by timely and effective corrective actions where needed. A minimal change in the cost of fortified food is ideal. Initially, absorption of the additional cost of fortification by the private sector or through government subsidies may be necessary. Ultimately, the long-term sustainability of fortification programmes is ensured when consumers are willing and able to bear the additional cost of fortified foods.

There has been an enormous increase in the number of fortification programmes in developing countries over the last couple of decades. With increasing urbanization this trend will continue. Considerable progress has been made in reducing vitamin $\mathrm{A}$ and I deficiencies, although less so with $\mathrm{Fe}$, even as $\mathrm{Zn}$ and folic acid deficiencies are emerging as important public health problems. The recently-formed global forum on fortification, GAIN, is made up of multilateral organizations, bilateral agencies (Canada, USA) and the private sector, including the food industry and the Gates Foundation, suggesting a new level of identification of fortification as an important strategy in the less-industrialized world. Food fortification based on sound principles and supported by clear policies and regulations will play an increasingly large role in the progress towards prevention and control of micronutrient malnutrition.

\section{Acknowledgements}

The paper was written based on the experience of the two authors and the referenced literature. However, many of the most recent field reports and experiences were taken from monthly updates from the Micronutrient Initiative, the MOST Project of USAID, and Helen Keller International. I.D.-H. is currently with WHO as a Senior Global Health Leadership Fellow and R.N. is currently with the US Food and Drug Administration. The opinions expressed herein are those of the authors and do not necessarily reflect the views of either the World Health Organization or the US Food and Drug Administration.

\section{References}

Arroyave G, Aguilar J, Flores M \& Guzman MA (1979) Evaluation of Sugar Fortification with Vitamin A at the National Level. Washington, DC: PAHO.
Ash DM, Latham MC, Tatala SR, Mehansho H, Ndossi N \& Frongillo EA Jr (1999) Trial of a micronutrient fortified beverage supplement in school children and pregnant women in Tanzania. XIXth IVACG Report Vitamin A and other Micronutrients: Biologic Interactions and Integrated Interventions, W23:90Abstr. Washington, DC: IVACG/USAID/ILSI Research Foundation.

Asian Development Bank/Micronutrient Initiative/International Life Sciences Institute (2000) Consensus Statement of the Manila Forum on Food Fortification Policy. Manila, The Philippines: Asian Development Bank.

Beard J (1996) Iron fortification in Venezuela. American Journal of Clinical Nutrition 64, 972-973.

Bishai D \& Nalubola R (2002) The history of food fortification in the United States: its relevance for current fortification efforts in developing countries. Economic Development and Cultural Change (In the Press).

Bürgi H (1998) Iodine deficiency disorders in Switzerland. In Elimination of Iodine Deficiency Disorders (IDD) in Central and Eastern Europe, the Commonwealth of Independent States, and the Baltic States. WHO/EURO/NUT/98.1, pp. 15-19 [F Delange, A Robertson, E McLoughney and $\mathrm{G}$ Gerasimov, editors]. Geneva: WHO.

Caudill MA, Le T, Moonie SA, Torabian Esfahani S \& Cogger EA (2001) Folate status in women of childbearing age residing in Southern California after folic acid fortification. Journal of the American College of Nutrition 20, 129-134.

Center for Disease Control (2001) CDC Press Release (June 19, 2001) Neural Tube Birth Defects Down by 19 Percent Since Food Fortification. Fortification, Educational Outreach and More Awareness May Contribute to Decline. Atlanta, GA: CDC.

Darnton-Hill I (1989) Vitamin A fortification of wheat: Bangladesh experience. Latest Advances in the Control of Vitamin A Deficiency and its Impact on Health. Government of Indonesia/WHO, SEARO/HKI. Report of a Regional Workshop pp. 121-135. Bogor, Indonesia: Nutrition Research and Development Centre.

Darnton-Hill I (1998) Overview: rationale and elements of a successful food-fortification programme. Food and Nutrition Bulletin 19, 92-100.

Darnton-Hill I, Mora JO, Weinstein H, Wilbur S \& Nalubola PR (1999) Iron and folate fortification in the Americas to prevent and control micronutrient malnutrition: an analysis. Nutrition Reviews 57, 25-31.

Dary O (2001) Free Trade vs Public Health: the history of the fighting for the sugar fortification program in Guatemala. XXth, IVACG Report 25 Years of Progress in Controlling Vitamin A Deficiency: Looking to the Future, W5:59 Abstr. Washington, DC: IVACG/USAID/ILSI Research Foundation.

Delange F (1998) Monitoring of programmes of correction of IDD. In Elimination of Iodine Deficiency Disorders (IDD) in Central and Eastern Europe, the Commonwealth of Independent States, and the Baltic States. WHO/EURO/NUT/98.1, pp. 103-116 [F Delange, A Robertson, E McLoughney and G Gerasimov, editors]. Geneva: WHO.

Ferrer F (2001) VivaLeite program improves Brazilian children's quality of life. Nutriview 2,3 .

Fidler M, Davidsson L, Walczyk T \& Hurrell R (2001) Iron bioavailability from iron fortified fish sauce and soy sauce. $X X t h$ IVACG Report 25 Years of Progress in Controlling Vitamin A Deficiency: Looking to the Future, F40:28 Abstr. Washington, DC: IVACG/USAID/ILSI Research Foundation.

Food and Agriculture Organization (1996) Food Fortification: Technology and Quality Control. Report of an FAO Technical Meeting, Rome, 20-23 November 1995. FAO Food and Nutrition Paper. Rome: FAO. 
Gerasimov G \& Delange F (1998) Overview of iodine deficiency disorders (IDD) and their control programmes in Eastern Europe and Central Asia. In Elimination of Iodine Deficiency Disorders (IDD) in Central and Eastern Europe, the Commonwealth of Independent States, and the Baltic States. WHO/EURO/NUT/98.1, pp. 7-13 [F Delange, A Robertson, E McLoughney and G Gerasimov, editors]. Geneva: WHO.

Harvey PWJ, Dexter PB \& Darnton-Hill I (2000) The impact of consuming iron from non-food sources on iron status in developing countries. Public Health Nutrition 3, 375-383.

Hollowell JG, Staehling NW, Hannon WH, Flanders DW, Gunter EW, Maberly GF, Braverman LE, Pino S, Miller DT, Garbe PL, DeLozier DM \& Jackson RJ, (1998) Iodine nutrition in the United States. Trends and public health implications: iodine excretion data from the National Health and Nutrition Examination Surveys I and III (1971-1974 and 1988-1994). Journal of Clinical Endocrinology and Metabolism 83, 3401-3408.

Honein MA, Paulozzi LJ, Mathews TJ, Erickson JD \& Wong L-YC (2001) Impact of folic acid fortification of the US food supply on the occurrence of neural tube defects. Journal of the American Medical Association 285, 2981-2986.

Huffman SL, Baker J, Shumann J \& Zehner ER (1998) The Case for Promoting Multiple Vitamin/Mineral Supplements for Women in Underdeveloped Countries. Washington, DC: LINKAGES Project/USAID. AED/PSI.

Institute of Medicine (1998) Prevention of Micronutrient Deficiencies: Tools for Policy Makers and Public Health Workers. Summary and Key Elements [CP Howson, ET Kennedy and A Horwitz, editors]. Washington, DC: National Academy Press.

International Council for the Control of the Iodine Deficiency Disorders (2000a) Salt 2000: marking and sustaining global progress in Universal Salt Iodization. IDD Newsletter 16, 34-37.

International Council for the Control of the Iodine Deficiency Disorders (2000b) Reports from the Regions. Africa. IDD Newsletter 16, 25-28.

Johnson Q (2000) Fortifying flour to improve world health. World Grain. November issue. Bangkok: World Grain Co. Ltd. www.world grain.com

Layrisse M, Chavez JF, Mendez-Castellano H, Bosch V, Tropper E, Bastardo B \& Gonzalez E (1996) Early response to the effect of iron fortification in the Venezuelan population. American Journal of Clinical Nutrition 64, 903-907.

Lindsey D \& Kwaramba T (2001) Making hammermill fortification at community level work. Nutriview $2,2$.

Lotfi M, Mannar MGV, Merx RJHM \& Naber-van den Heuvel P (1996) Micronutrient Fortification of Foods: Current Practices, Research, and Opportunities. Ottawa, Ont.: MI/LAC.

McNulty H (1999) Towards improving dietary intakes and health: the contribution of fortified foods. Scandinarian Journal of Nutrition 43, Suppl. 35, 106S-111S.

Mason J, Hunt J, Parker D \& Jonsson U (1999) Investing in child nutrition in Asia. Asian Development Review 17, 1-32.

Mason JB, Lotfi M, Dalmiya N, Sethuramanan K \& Deitchler M (2001) The Micronutrient Report: Current Progress and Trends in the Control of Vitamin A, Iodine and Iron Deficiencies. Tulane University/MI/UNICEF. Ottawa, Ont.: Micronutrient Initiative.

Melse-Boonstra A, de Pee S, Martini E, Halati S, Sari M, Kosen S, Muhilal \& Bloem MW (2000) The potential of various foods to serve as a carrier for micronutrient fortification, data from remote areas in Indonesia. European Journal of Clinical Nutrition 54, $822-827$.

Meng W \& Schindler A (1998) Iodine supply in Germany. In Elimination of Iodine Deficiency Disorders (IDD) in Central and Eastern Europe, the Commonwealth of Independent States, and the Baltic States. WHO/EURO/NUT/98.1, pp. 21-30 [F Delange,
A Robertson, E McLoughney and G Gerasimov, editors]. Geneva: WHO.

Micronutrient Initiative (1997) Food Fortification to End Micronutrient Malnutrition: State of the Art. Ottawa, Ont.: Micronutrient Initiative.

Micronutrient Initiative/UNICEF/International Sugar Organization/USAID/Swaziland Sugar Association (1999) Sugar Fortification to End Vitamin A Deficiency in Southern and Eastern Africa. Report of a Public/Private Sector Dialogue, Ezulwini, Swaziland. Ottawa, Ont.: Micronutrient Initiative.

Mora JO, Dary O, Chinchilla D \& Arroyave G (2000) Vitamin A Sugar Fortification in Central America. Experiences and Lessons Learned. Washington, DC: MOST/USAID/INCAP/ PAHO.

Muhilal, Permesieh D, Idjaradimata Y, Muherdiyantingsih \& Karyadi D (1988) Vitamin A-fortified monosodium glutamate and health, growth and survival of children: a controlled trial. American Journal of Clinical Nutrition 48, 1271-1276.

Murphy PA (1996) Technology of vitamin A fortification of foods in developing countries. Food Technology 50, 69-74.

Nalubola R (2000) Safety of Vitamin A Fortification of Foods: a brief review. Washington, DC: MOST/USAID.

Nathan R (2000) Regulation of Fortified Foods to Address Micronutrient Malnutrition: Legislation, Regulations, and Enforcement. Ottawa, Ont.: Micronutrient Initiative.

Nestel P (1993) Food Fortification in Developing Countries. New York: USAID/VITAL.

Nutriview (2000) Nutriview Special Issue. Mandatory Food Enrichment. Basel: Roche Vitamins Europe Ltd.

Nutriview (2001) Food fortification gains support in Africa. Nutriview Newsletter, vol. 1, p. 3. Basel: Roche Vitamins Europe Ltd.

Ong ASH (1994) Nutritional aspects of palm oil: an introductory review. Asia Pacific Clinical Nutrition 3, 201-206.

Park YK, Sempos CT, Barton CN, Vanderveen JE \& Yetley EA (2000) Effectiveness of food fortification in the United States: the case of pellagra. American Journal of Public Health 90, 727-738.

Sari M, Bloem MW, de Pee S, Schultink WJ \& Sastroamidjojo S (2001) Effect of iron-fortified candies on the iron status of children aged 1-4y in East Jakarta, Indonesia. American Journal of Clinical Nutrition 72, 1034-1039.

Serra-Majem L (2001) Vitamin and mineral intakes in European children. Is food fortification needed? Public Health Nutrition 4, 101-107.

Solomons NW (1998) Plant sources of vitamin A and human nutrition: red palm oil does the job. Nutrition Reviews 56, 309-311.

Solon FS, Bernardo ABI, Sarol JN, Solon JA, Mehanso H, Fermin LS \& Wambangco (2001) The effect of a multiple micronutrient fortified fruit drink with and without antihelmentic therapy on growth, fitness and mental ability of Filipino school children. XXth IVACG Report 25 Years of Progress in Controlling Vitamin A Deficiency: Looking to the Future, F41: 28 Abstr. Washington, DC: IVACG/USAID/ILSI Research Foundation.

Solon FS, Klemm RDW, Sanchez L, Damton-Hill I, Craft NE, Christian P \& West KP Jr (2000) Efficacy of a vitamin A-fortified wheat-flour bun on the vitamin A status of Filipino schoolchildren. American Journal of Clinical Nutrition 72, 738-734.

Solon FS, Solon MS, Mehansho H, West KP Jr, Sarol J, Perfecto C, Nano T, Sanchez L, Isleta M, Wasantwisut E \& Sommer A (1996) Evaluation of the effect of vitamin A-fortified margarine on the vitamin A status of pre-school Filipino children. European Journal of Clinical Nutrition 56, 720-723.

Thuy PV, Berger J, Davidsson L, Khan NC, Nga TT, Lam NT, Mai TT, Flowers C, Nakanish Y, Cook JD, Hurrell RF \& Khoi HH 
(2001) Regular consumpton of NaFeEDTA fortified fish sauce improves hemoglobin in anemic Vietnamese women. XXth IVACG Report 25 Years of Progress in Controlling Vitamin A Deficiency: Looking to the Future, F47: 30Abstr. Washington, DC: IVACG/USAID/ILSI Research Foundation.

Todd CH, Ammain T, Gomo ZAR, Hasker JA, Ndiweni M \& Oken E (1995) Increase in thyrotoxicosis associated with iodine supplements in Zimbabwe. Lancet 346, 1563-1564.

UNICEF (1990) World Declaration on the Survival, Protection and Development of Children. The World Summit for Children. New York: UNICEF

UNICEF/World Health Organization/United Nations University (1999) Composition of a Multi-micronutrient Supplement to be Used in Pilot Programmes Among Pregnant Women in Developing Countries. New York: UNICEF.

van Stuijvenberg ME, Kvalsvig JD, Faber M, Vorster N \& Benade AJS (1997) The Hidden Hunger: Addressing Micronutrient
Deficiencies in School Children. Medical Research Council of South Africa: Policy Briefs no. 4. Capetown, South Africa: Medical Research Council of South Africa.

World Bank (1993) Investing in Health. World Development Report 1993. New York: Oxford University Press.

World Health Organization (1995) Nutrition. Highlights of Recent Activities in the Context of the World Declaration and Plan of Action for Nutrition. Geneva: WHO.

Zlotkin S, Arthur P, Antwi KY \& Yeung G (2001) Randomized controlled trial of microencapsulated ferrous fumarate 'sprinkles' and ferrous sulfate drops, for the treatment and prevention of anemia in Ghanaian infants. XXth IVACG Report 25 Years of Progress in Controlling Vitamin A Deficiency: Looking to the Future, F47:30Abstr. Washington, DC: IVACG/USAID/ILSI Research Foundation. 